\title{
An integrated grey AHP-MOORA model for ameliorating public transport service quality
}

\author{
Sarbast Moslem ${ }^{1 *}$ (D) and Yakup Çelikbilek ${ }^{2}$
}

\begin{abstract}
Introduction: Public transport systems provide essential mobility service to citizens who do not have access to private cars. Public transport also plays a significant role in minimizing road congestions, air pollution, journey time and energy consumption. Public transport service quality need efficient strategic plans to be able to increase user's satisfaction and attract non-user's.
\end{abstract}

Objectives: To achieve this target, a combined model of the Analytic Hierarchy Process (AHP) with Multi Objective Optimization Method by Ratio Analysis (MOORA) based on grey optimization has been adopted, as a case study, the public bus transport system in Budapest, Hungary has been opted.

Methods: The weight scores of the evaluation criteria are conducted based on transport experts' assessments. When the studies in the literature are reviewed, it is observed that the success of the MOORA technique about decision making is remarkable. Also, there is not an agreed and validated grey MOORA technique in the literature. Thus, an integrated grey AHP and grey MOORA technique is proposed in this study to evaluate the public transport service quality. Grey based multi-criteria decision making methods are very useful to decrease the subjectivity of the decision makers.

Results: The importance of criteria has been computed by conducting grey AHP approach while the alternatives that have been preferred mostly within the certain criteria have been estimated by adopting grey MOORA method. Finally, the findings of the proposed model shed the light on "Provide new buses" as the most desired alternative for developing the service quality of public bus transport in Budapest.

Conclusion: The proposed model provides reliable and robust results for improving public transport service quality. The local government representatives in Budapest may use the obtained results in their future strategic plans for developing public bus transport system.

Keywords: Public transport, Service quality, Grey systems, Grey analytic hierarchy process, Grey MOORA

\section{Introduction}

Public transport system amelioration is becoming the focal point for government local representatives, because of the sprawling urbanization phenomena which have critical impacts on many sides in everyday life. Public

\footnotetext{
* Correspondence: moslem.sarbast@mail.bme.hu

'Budapest University of Technology and Economics, Department of Transport Technology and Economics, Múegyetem rkp 3, Budapest 1111, Hungary

Full list of author information is available at the end of the article
}

transport conveys many more users in much less space than personal cars, which is keeping traffic congestion lower, and also it decreases air pollution per passenger $\mathrm{km}$ than the standard personal cars which carrying single passenger according to American Public Transport Association (APTA), which interns bridle the greenhouse gases increase within acceptable limits. It impacts positively the economic, where users can save individuals a significant amount of money each year in avoided fuel,

\section{Springer Open}

(0) The Author(s). 2020 Open Access This article is licensed under a Creative Commons Attribution 4.0 International License, which permits use, sharing, adaptation, distribution and reproduction in any medium or format, as long as you give appropriate credit to the original author(s) and the source, provide a link to the Creative Commons licence, and indicate if changes were made. The images or other third party material in this article are included in the article's Creative Commons licence, unless indicated otherwise in a credit line to the material. If material is not included in the article's Creative Commons licence and your intended use is not permitted by statutory regulation or exceeds the permitted use, you will need to obtain permission directly from the copyright holder. To view a copy of this licence, visit http://creativecommons.org/licenses/by/4.0/. 
maintenance, parking, taxes and other expenses. Public transport is safer, not only in terms of the safety of the vehicles themselves, which are maintained much more regularly than individual automobiles, but also in terms of the time by spending transit time on reading, working, studying or many other activities or just take a nap. However, improving the efficiency of public transport system supply quality has consequently come to be considered of paramount essential issue not only because it increases users' satisfaction, but also it attracts new users which interns impact the community psychologically and economically.

To a certain degree the logicalness of any organizational strategy relays on the users, what is logical for one user may be illogical for others. In urban transport service case the objective is to design an efficient strategy for users by involving urban transport managers and planners, but the strategy should also be practical for scholars to obtain useful information to add it to the database. The categorization strategy should be easy to utilize; otherwise it will not be used and will not serve as a useful tool for promoting implementation of public transport efficiency improvement strategies.

Passengers' perception of public transport service has gained increasing attention [6]. It is currently admitted that passengers' point of view should supplement the usual indicators of quality in public transport service [44]. Passenger expression is a significant source of information in detecting the problems and developing effective strategic plans of action for quality improvement for public transport service. Assessing satisfaction has been mandatory for urban transport services $[32,60]$.

The perceived quality of a public transport service is the only target information for operating companies and this quality depends on several factors related to the service itself, such as, reliability [53], frequency [34], punctuality [15] and factors related to terminals and vehicles, such as, cleanliness [61], safety [14], comfort [9].

More recently, many scholars thoroughly proposed and focused the attention on the service quality of public transport and improving the system efficiency though using different methodologies, such as, Structural Equation Model (SEM), factor analysis, multiple logit approaches, Bayesian and Markov chain Monte Carlo approaches. Lai and Chen [39] argued the need for marketing strategies to rise transport system users. Lai and Chen [39] conducted multiple regression approach for ameliorating the service quality of Kaohsiung urban rail transit system. Mokonyama and Venter [43] also applied conjoint analysis to enhance service quality of public transport, however, three different evaluator groups participated in survey to reflect the real demand for each of them. De Oña et al. (2013) [17] conducted the SEM approach to evaluate the public transport service quality criteria in Granada, Spain. Friman et al. (2013) [28] adopted factor analysis method to rise public transport system's efficiency and created a public transport service satisfaction index measurement. Yaya et al. [64] respectively adopted structural equation modeling (SEM), Mann-Whitney $U$ and Kruskal-Wallis approaches to evaluate public bus transport service quality where 288 participants from different groups involved in the survey. Allen et al. [2] estimated the relationship between public transport users' satisfaction and loyalty by conducting SEM and SEM Multi-Group Analysis, which verifies as an efficient tool to detect for heterogeneity in satisfaction by time, age and travel frequency. Their study spotted the light on Loyalty affection on service quality criteria. For ameliorating the railway service quality offered in the hinterland of Milan, Allen et al. [3] used full Structural Equation Multiple Cause Multiple Indicator (SEM-MIMIC) model, which corrects for heterogeneity in the perceptions of users regarding satisfaction with the various service attributes, with the overall service, and with loyalty. The improvements will ultimately attract new users and lead to more sustainable system. Tsionas et al. (2017) [59] respectively utilized Bayesian and Markov chain Monte Carlo methods to enhance the U.S. airline industry supply quality. Nesheli et al. [47] respectively used the conjoint model to shed the light on the importance of reliability as a significant service quality criteria of public transport in two mega cities, Lyon, France and Auckland, New Zealand. To recognized passengers real demand and reduce the gap between local government representatives' and citizens', Duleba and Moslem [23] pointed out the demand of improving public bus transport and highlighted the differences in preferences among different stakeholder groups. These views are shared by Hutchinson [33] when pointing out the difference between citizens and operators point of views toward developing transportation system. Kujala et al. [37] applied the concept of Pareto optimality journey alternatives to evaluate public transport system through analyzing travel time and measuring the expected transfers number. Sun et al. [54] emphasized the service quality impact on user satisfaction, especially with bus stops and waiting time, as a methodology, they used asymmetric importanceperformance analysis.

Adopting Multi Criteria Decision Making (MCDM) methodologies for improving the service quality of public transportation highlights significant recognition of subjective impact issues on the final ranking of alternatives. Another significant issue for implementing MCDM methodologies in the area of public transportation is that they can deal with such complex issues with limited requirements. 
In real world complex problems, the vagueness enhances because of the inconvenient human decisions and imprecise information. Grey systems theory is a significant methodology that provide to integrate uncertainty and ambiguity into the evaluation process [62].

The aim of this study is to prioritize public bus transport service quality criteria and shed the light on the most significant alternative for improving service quality of public bus transport system. As a methodology, the Grey Analytic Hierarchy Process (Grey AHP) approach has been conducted in order to rank the most important service quality criteria for public bus transportation system, moreover, Multi-Objective Optimization Method by Ratio Analysis (MOORA) has been applied to contrive the appropriate alternative for supporting future decision strategic plan. The prioritization has been done separately by transport experts who are real users for public bus transport in Budapest city, Hungary.

\section{Literature review on MCDM methodologies and public transport service quality}

The supply quality criteria of public transport system have been thoroughly investigated in the recent years. A specific attention has been paid to on-board physical and mental comfort $[1,18,31,42]$, system reliability [20, $27,53]$, system accessibility $[45,50]$, safety at stops [13, $26]$ and safety on-board $[8,48]$.

Multi Criteria Decision Making (MCDM) methodologies effectively implemented to public transportation system developing problem in literature, such that several types of MCDM methods have been used in different transport sectors to evaluate service quality, planning problems and selecting alternatives. One of the most and widely adopted approach to derive criteria weight scores in multicriteria evaluation is Analytic Hierarchy Process (AHP) approach. Saito [51] respectively utilized AHP to analyze bridge developing programs and different decision makers point of views were aggregated. Tracz and Wawrzynkiewicz [57] applied AHP to choose the most significant public transport system alternatives. Tabucanon and Lee [55], employed AHP to evaluate rural highway developing projects in Korea, highlighted the efficiency of AHP in providing much more balanced results than conventional economic evaluation approaches when many complex criteria are compared. Gercek et al. [29] used AHP to enumerate the alternatives of rail networks in Istanbul, Turkey. As a general form of AHP, Jharkharia and Shankar [35] used Analytic Network Process (ANP) for selection of a logistic service provider. Chang et al. [10] used ANP to select the best alternative revitalization strategies for the Alishan Forest Railway project. Ghorbanzadeh et al. [30], in their study of evaluation public bus transport supply quality improvement in Mersin, Turkey, conducted interval AHP approach, 24 criteria and subcriteria were estimated. Nalmpantis et al. [46] have proposed AHP approach to evaluate a set of innovation ideas for enhancing public transportation system and make it more attractive, the suggestions were recommended by the users and non-users.

However, the previous studies do not concern the uncertainty of decision data of evaluator behavior. To overcome the subjectiveness of evaluator behavior, Chang and Yeh (2002) [11] respectively adopted TOPSIS based on the concept of fuzzy set theory to improve service quality of airlines in terms of users' point of views. The alternatives ranking support airlines operators in their future strategic plans. Tsaur et al. (2002) [58] proposed AHP and TOPSIS approaches based on fuzzy sets to enumerate service performance criteria weights and obtain alternatives ranking. They found that the fuzzy set theory can be employed very effectively to enumerate service performance. Lupo [41] used an integrated AHP approach with fuzzy set theory to ameliorate transportation service quality in Palermo, Italy. For enumerating risk factor of urban rail transport system in Tehran, Iran, Baradaran [4] proposed AHP based on the grey number scores, the model can help to complete the uncertainty of evaluators answers and incomplete information in the survey. Li et al. [40] focused on evaluating in-flight service quality which consider essential part in the air travel service process in China, they used fuzzy AHP based on 2-Tuple fuzzy linguistic method. Moslem et al. [44] used triangular fuzzy set with interval AHP to evaluate the supply quality criteria related to public bus transport system in Mersin, Turkey. The conducted results illustrated the efficiency of the proposed model to deal with vague concepts in the available data.

\section{The proposed integrated grey AHP-MOORA model}

The proposed integrated grey AHP-MOORA model is introduced in this section. In the first sub-section, grey AHP (Analytic Hierarchy Process) method is explained in detail step by step. And then, in the second subsection, grey MOORA (Multi-Objective Optimization on the basis of Ratio Analysis) method is explained in detail step by step.

\subsection{The analyzed criteria of public bus transport service quality}

The focal point of this study is proposing an empirical case to evaluate the service quality being one of the most important main supply quality criteria of public bus transport. For this aim, 5 main criteria of public bus transport service quality (Approachability, Directness, Reliability, Time availability and Speed) and 10 subcriteria have been obtained from experts' perspective and from literature (Table 1). As a methodology, AHP 
Table 1 The analyzed criteria of public bus transport service quality

\begin{tabular}{|c|c|c|c|}
\hline Main criteria & Sub-criteria & Definition & Reference \\
\hline \multirow[t]{3}{*}{$\begin{array}{l}\text { Approachability } \\
\text { C1 }\end{array}$} & $\begin{array}{l}\text { Directness to stops } \\
\text { C1.1 }\end{array}$ & Arriving the stops for travel & Duleba et al. [22]; Saif et al. [50] \\
\hline & $\begin{array}{l}\text { Safety of stops } \\
\text { C1.2 }\end{array}$ & User' safety pre-travel at stops & $\begin{array}{l}\text { Eboli and Mazzulla, [26]; } \\
\text { Cheranchery et al. [13] }\end{array}$ \\
\hline & $\begin{array}{l}\text { Comfort in stops } \\
\text { C1.3 }\end{array}$ & heating and cooling systems, seats & Miao et al. [42]; Sun et al. [54] \\
\hline \multirow[t]{2}{*}{$\begin{array}{l}\text { Directness } \\
\text { C2 }\end{array}$} & $\begin{array}{l}\text { Need for transfer } \\
\text { C2.1 }\end{array}$ & User demand to change service type or not & Cheng and Tseng, [12] \\
\hline & $\begin{array}{l}\text { Fit connection } \\
\text { C } 2.2\end{array}$ & $\begin{array}{l}\text { The interaction between bus lines or between } \\
\text { buses and other types of public services }\end{array}$ & Dimitrov et al. [21]; Jin et al. [36] \\
\hline $\begin{array}{l}\text { Reliability } \\
\text { C3 }\end{array}$ & & $\begin{array}{l}\text { The quality of trust deserving, through } \\
\text { delivering the promised services accurately and } \\
\text { on specified time }\end{array}$ & Diab et al. [20]; Soza-Parra et al. [53] \\
\hline \multirow[t]{2}{*}{$\begin{array}{l}\text { Time availability } \\
\text { C4 }\end{array}$} & $\begin{array}{l}\text { Frequency of lines } \\
\text { C4.1 }\end{array}$ & $\begin{array}{l}\text { Number of times that public transportation is } \\
\text { deployed over a route }\end{array}$ & Deng \& Yan [19] \\
\hline & Limited time of use C 4.2 & $\begin{array}{l}\text { Time of starting the service and stopping service } \\
\text { during the day }\end{array}$ & Scott et al. [52] \\
\hline \multirow[t]{3}{*}{$\begin{array}{l}\text { Speed } \\
\text { C5 }\end{array}$} & $\begin{array}{l}\text { Travel time } \\
\text { C5.1 }\end{array}$ & $\begin{array}{l}\text { Duration of time spent by users on-board } \\
\text { between origin-destination points }\end{array}$ & $\begin{array}{l}\text { Tétreault \& El-Geneidy [56]; } \\
\text { Kujala et al. [37] }\end{array}$ \\
\hline & $\begin{array}{l}\text { Awaiting time } \\
\text { C5.2 }\end{array}$ & Pre-travel waiting time for the service at stops & $\begin{array}{l}\text { Ingvardson et al. [34]; } \\
\text { Kujala et al. [37] }\end{array}$ \\
\hline & $\begin{array}{l}\text { Reaching time } \\
\text { C5.3 }\end{array}$ & Duration of time spent by users to reach stops & Currie [16]; Ingvardson et al. [34] \\
\hline
\end{tabular}

approach based on the grey number scores used to determine weights of criteria, while MOORA method used to rank the alternatives, via expert surveys. The 10 experts are selected from the faculty of transportation engineering to boost the objectivity of the results as much as possible. The presented approach supports local government representatives in their future developing strategic plans for public bus transportation system to further improve service quality.

\subsection{The Grey analytic hierarchy process}

Analytic Hierarchy Process was firstly introduced by Saaty in 1977 [49]. AHP method has an increasing usage since the day it was first introduced. It has used to form the basis of the other MCDM (Multi-Criteria Decision Making) methods and also integrated with the other methods. In recent years, the grey and fuzzy methods has been being developed for the group decision making and to decrease the subjective judgements in the MCDM process. However, totally grey AHP and grey MOORA methods have not been developed and also used in public transportation applications. Wang and Liu [62] was proposed a grey AHP method to evaluate the urban public traffic line network. But, in the proposed grey AHP method, the authors whitened the grey evaluations right after obtaining the grey evaluations. So, the authors continued the calculations of the evaluations by using classic AHP method. We cannot say it was a totally grey AHP method from the pairwise comparisons to the final ranking results.

In this study, the public transport service quality has been evaluated by using the proposed grey AHP and grey MOORA methods, in which grey numbers are used, instead of the classic AHP and classic MOORA methods, in which classic numbers are used. The proposed grey AHP method used in this study is introduced step by step below (Fig. 1).

\subsubsection{Step 1: defining the problem}

Solutions of all problems start with the complete definition of the problems. In MCDM problems, the calculations are started by defining the aim of the problem, alternatives and criteria.

\subsubsection{Step 2: constructing the hierarchical structure}

The hierarchical structure of the problem is constructed by using the aim, alternatives and criteria of the problem.

\subsubsection{Step 3: pairwise comparisons}

If the problem has no decision matrix, pairwise comparisons among the criteria and the alternatives are done by using the linguistic scale given in Table 2. Importance values of the AHP method are between one and nine which are from equally important to absolutely 


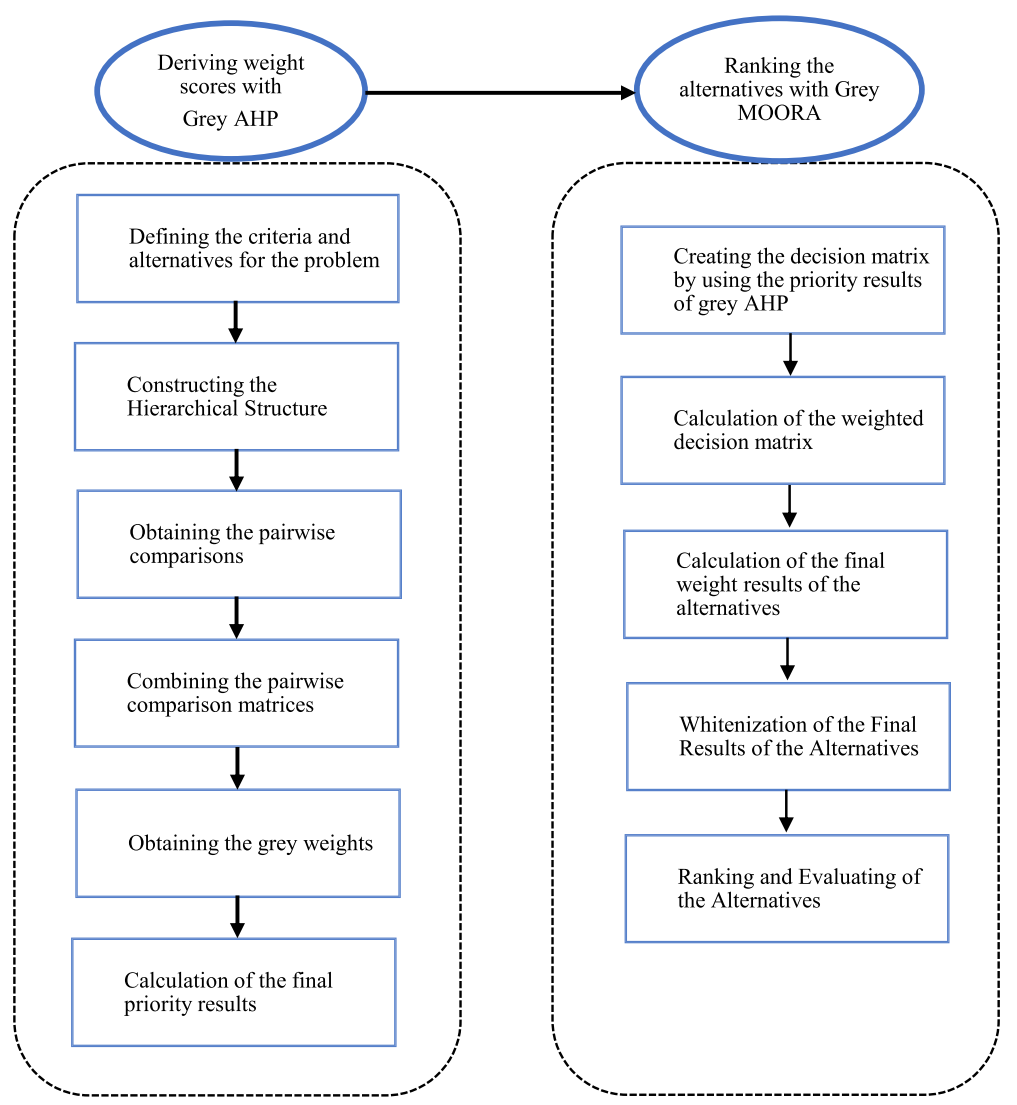

Fig. 1 The framework of the proposed grey AHP-MOORA method

important. The grey number representations of the linguistic scales used in the grey AHP calculations are given in Table 2 in detail.

An example of a pairwise comparison matrix done by the decision maker $d$ is given in the following Eq. (1). $\otimes a_{i j}^{d}=\left[a_{i j}^{d}, \overline{a_{i j}^{d}}\right]$ represents the pairwise comparison of the $i$ th criterion and $j$ th criterion done by decision maker $d$. $D$ represents the set of decision makers, which are $D=\{1,2, \ldots, d, \ldots, D\}$. All of the pairwise comparisons are done for the upper part of the main diagonal. The lower parts of the main diagonal are filled by using the opposite forms to multiplication operation of the pairwise comparisons at the upper part of the main diagonal. Eq. (2) is used to fill the

Table 2 Linguistic scales and the grey numbers used for the pairwise comparisons of grey AHP

\begin{tabular}{lll}
\hline Importance value & Linguistic scales & Grey number \\
\hline 1 & Equally Important & {$[1,2]$} \\
3 & Weakly Important & {$[2,4]$} \\
5 & Important & {$[4,6]$} \\
7 & Strongly Important & {$[6,8]$} \\
9 & Absolutely Important & {$[8,9]$} \\
\hline
\end{tabular}

lower parts of the pairwise comparisons and the main diagonal of the pairwise comparison matrix is filled by using the equation given in Eq. (3).

$$
\begin{aligned}
& A_{g}^{d}=\left[\begin{array}{cccccc}
\otimes a_{11}^{d} & \otimes a_{12}^{d} & \cdots & \otimes a_{1 j}^{d} & \cdots & \otimes a_{1 n}^{d} \\
\otimes a_{21}^{d} & \otimes a_{22}^{d} & \cdots & \otimes a_{2 j}^{d} & \cdots & \otimes a_{2 n}^{d} \\
\vdots & \vdots & \ddots & \vdots & \ddots & \vdots \\
\otimes a_{i 1}^{d} & \otimes a_{i 2}^{d} & \cdots & \otimes a_{i j}^{d} & \cdots & \otimes a_{i n}^{d} \\
\vdots & \vdots & \ddots & \vdots & \ddots & \vdots \\
\otimes a_{n 1}^{d} & \otimes a_{n 2}^{d} & \cdots & \otimes a_{n j}^{d} & \cdots & \otimes a_{n n}^{d}
\end{array}\right] \\
& \otimes a_{i j}^{d}=\left[\frac{1}{\bar{a}_{i j}^{d}}, \frac{1}{\underline{a}_{i j}^{d}}\right] \\
& \otimes a_{i i}^{d}=[1,1]
\end{aligned}
$$

\subsubsection{Step 4: combining the pairwise comparison matrices}

The pairwise comparison matrices done by decision makers are combined by using the Eq. (4). Eq. (4) is the geometric mean formulation, which is not affected by very high and very low values of the pairwise comparison matrices. Barzilai [5] determined that the geometric mean is the only method for deriving weights from multiplicative pairwise comparisons which 
satisfies fundamental consistency requirements. And also, the geometric mean is the only solution preserving the strong algebraic structure of the problem and is naturally consistent with the arithmetic mean solution in the additive case [5]. The calculation is similar with classic AHP, which is also combined by using the geometric mean formulation. But, the calculations are done for the lower and the upper limits of the grey numbers separately. After combining all of the pairwise comparison matrices, the combined pairwise comparison matrices can be shown as $A_{g}=\left[\otimes a_{i j}\right]_{n x n}$ without using the decision maker number.

$$
\otimes a_{i j}=\sqrt[D]{\prod_{d=1}^{D} \otimes a_{i j}^{d}}
$$

\subsubsection{Step 5: normalization}

The normalization for the grey numbers, given in Eqs. (5)-(7), is adapted from the normalization of fuzzy numbers given by $\mathrm{Wu}$ and Lee [63].

$$
\begin{aligned}
& \otimes \underline{a_{i j}}=\frac{\left(\otimes \underline{a_{i j}}-\min _{j} \otimes \underline{a_{i j}}\right)}{\Delta_{\min }^{\max }} \\
& \otimes \overline{a_{i j}}=\frac{\left(\otimes \overline{a_{i j}}-\min _{j} \otimes \underline{a_{i j}}\right)}{\Delta_{\min }^{\max }} \\
& \Delta_{\min }^{\max }=\max \otimes \overline{a_{i j}}-\min \otimes \underline{a_{i j}}
\end{aligned}
$$

\subsubsection{Step 6: obtaining the grey weights}

Averages of the rows are calculated by using the Eq. (8) to obtain the weights and the priority vectors of the criteria set $C=\{1,2, \ldots, C\}$. In this study, the following steps are not used for the calculation of the final weights, but given here for the unity of the grey AHP method. The final priority results are calculated by using the Grey MOORA, which is given in the following sub-section.

$$
\frac{\sum_{j=1}^{C} \otimes a_{i j}}{C}
$$

\subsubsection{Step 7: calculation of the final priority results}

After creating the decision matrix, which is the combination of the weights and the priority vectors, the final priority results of the alternatives are calculated by using the Eq. (9).

$$
\sum_{j=1}^{C} w_{j} \otimes a_{i j}
$$

\subsubsection{Step 8: whitenization of the final results}

This step includes the whitenization of the grey results to interpret and analyze them easier and better. First of all, the final results are normalized by using the Eqs. (5)-(7). After the normalization, whitenization is done by using Eqs. (10)-(11).

$$
\begin{aligned}
& Y_{i}=\frac{\otimes \underline{a_{i}}\left(1-\otimes \underline{a_{i}}\right)+\otimes \overline{a_{i}} \times \otimes \overline{a_{i}}}{1-\otimes \underline{a_{i}}+\otimes \overline{a_{i}}} \\
& a_{i}=\min \otimes \underline{a_{i}}+Y_{i} \Delta_{\text {min }}^{\max }
\end{aligned}
$$

\subsection{The grey MOORA}

The MOORA (Multi-Objective Optimization on the basis of Ratio Analysis) method was firstly introduced by Brauers and Zavadskas [7]. Although as the most recent MCDM method, MOORA has been being used in the applications frequently. However, there is not an agreed complete grey MOORA approach in the literature yet. Proposed grey MOORA approaches in the literature has not been validated or completely grey application of the MOORA method [25, 38].

The proposed grey MOORA method used in this study is introduced step by step below.

\subsubsection{Step 1: defining the problem}

Solutions of all problems start with the complete definition of the problems. In MCDM problems, the calculations are started by defining the aim of the problem, alternatives and criteria.

\subsubsection{Step 2: creating the decision matrix}

After defining of the problem, the solution can continue by using the existing decision matrix. If there is no decision matrix of the problem, the decision matrix can be created by using the grey AHP method given in the previous sub-section or the other methods given in the literature. In this study, the decision matrix is created by using the grey AHP method given in the previous sub-section. While $D$ represents the decision matrix, it can be shown as in the Eq. (12). In the following decision matrix, $m$ represents the number of the alternatives and $n$ represents the number of the criteria. 


$$
D=\left[\begin{array}{cccccc}
\otimes x_{11} & \otimes x_{12} & \cdots & \otimes x_{1 j} & \cdots & \otimes x_{1 n} \\
\otimes x_{21} & \otimes x_{22} & \cdots & \otimes x_{2 j} & \cdots & \otimes x_{2 n} \\
\vdots & \vdots & \ddots & \vdots & \ddots & \vdots \\
\otimes x_{i 1} & \otimes x_{i 2} & \cdots & \otimes x_{i j} & \cdots & \otimes x_{i n} \\
\vdots & \vdots & \ddots & \vdots & \ddots & \vdots \\
\otimes x_{m 1} & \otimes x_{m 2} & \cdots & \otimes x_{m j} & \cdots & \otimes x_{m n}
\end{array}\right]
$$

\subsubsection{Step 3: normalization}

Normalization according to the columns of the decision matrix is done as in classic MOORA method. The normalization of the grey decision matrix is done by using the Eq. (13) given below.

$$
\otimes x_{i j}=\frac{\otimes x_{i j}}{\sqrt{\sum_{i=1}^{m} \otimes x_{i j}^{2}}}
$$

\subsubsection{Step 4: calculation of the weighted decision matrix} All of the decision matrix is multiplied with the weights related with the columns. Let $\otimes x_{i j}^{w}$ be the weighted value of the $\otimes x_{i j}, w_{j}$ be the weight of the $j$ th column and $\otimes x_{i j}$ be the value of the $i$ th alternative according to the $j$ th criterion, the weighted decision matric is calculated by using the Eq. (14).

$$
\otimes x_{i j}^{w}=w_{j} \cdot \otimes x_{i j}
$$

\subsubsection{Step 5: calculation of the final weight results of the alternatives}

Calculation of the final weight result of the alternatives are carried out by subtracting the sum of the negative criteria from the sum of the positive criteria. Let $B$ be the benefit criteria set, $\mathrm{C}$ be the cost criteria set and $\otimes y_{i}$ be the final weight result of the $i$ th alternative, the calculation of the $\otimes y_{i}$ is given in Eq. (15).

$$
\otimes y_{i}=\sum_{j \in P} \otimes x_{i j}^{w}-\sum_{j \in N} \otimes x_{i j}^{w}
$$

\subsubsection{Step 6: whitenization of the final results of the alternatives}

As it is also explained in grey AHP, the whitenization of the grey results are done to interpret and analyze them easier and better. The whitenization of the final grey results are calculated by using the equations (Eqs. (5)-(7) and Eqs. (10)-(11)) given in the previous grey AHP subsection.

\subsubsection{Step 7: ranking and evaluating of the alternatives}

The subtraction of all alternatives are ranked from the highest to the lowest for the best alternatives. The best is the alternative with the highest subtraction value and the last preferable one is the alternative with the lowest subtraction value.

\section{The application for the public transport service quality}

The application of the proposed integrated method is to evaluate the public transport service quality. To this aim, grey based AHP and MOORA methods are introduced. The pairwise comparisons for the evaluations were done by the experts on public transport. Therefore, the effects of the subjective judgements of the experts have to be decreased during the analysis. Grey AHP method is

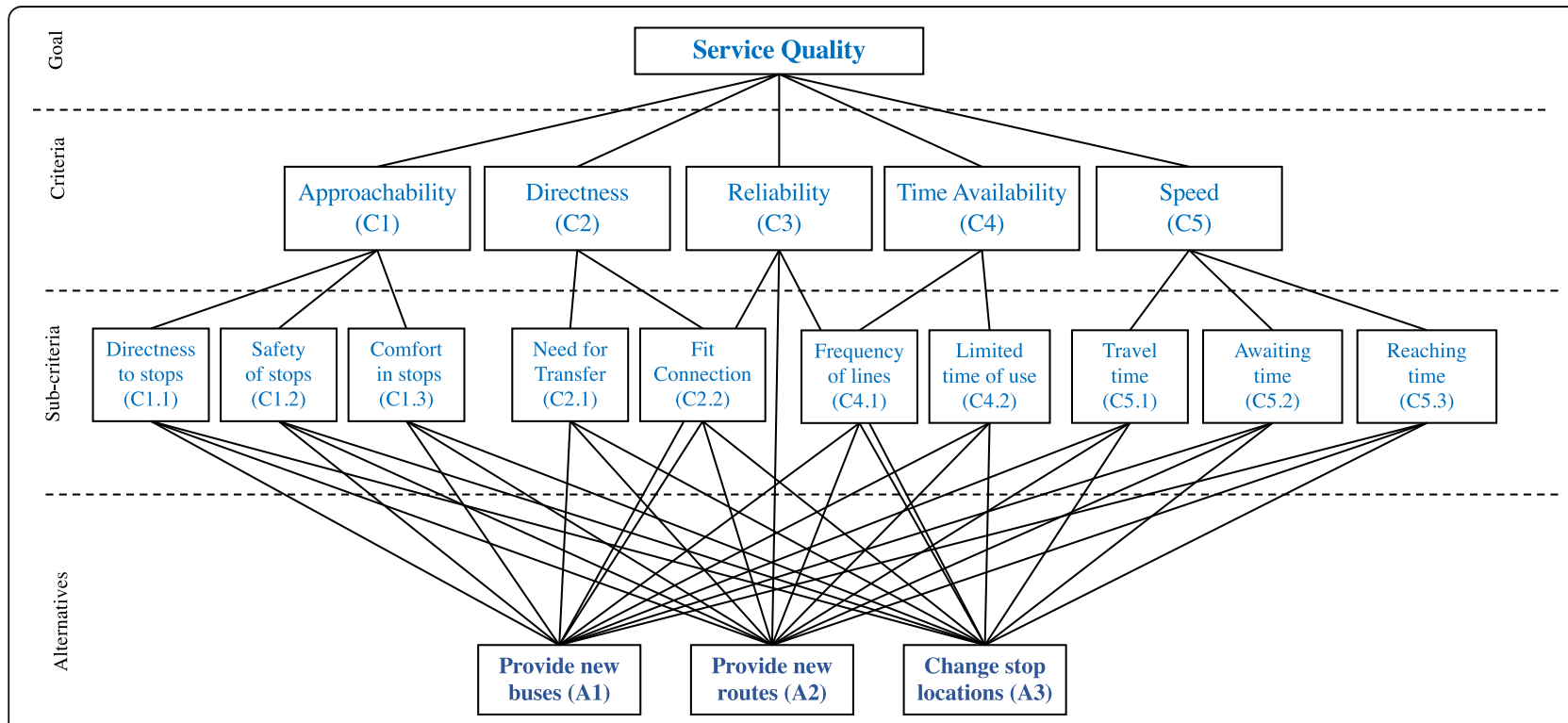

Fig. 2 The hierarchical structure of the public bus transport system service quality 
Table 3 Pairwise comparison matrix and grey weights of the main criteria

\begin{tabular}{lllllll}
\hline & C1 & C2 & C3 & C4 & C5 & Grey Weights \\
\hline C1 & {$[1.000,1.000]$} & {$[1.267,2.048]$} & {$[0.494,0.780]$} & {$[0.896,1.431]$} & {$[0.584,0.871]$} & {$[0.092,0.267]$} \\
C2 & {$[0.488,0.789]$} & {$[1.000,1.000]$} & {$[0.443,0.758]$} & {$[0.494,0.789]$} & {$[0.360,0.530]$} & {$[0.000,0.076]$} \\
C3 & {$[1.282,2.024]$} & {$[1.320,2.259]$} & {$[1.000,1.000]$} & {$[1.866,2.734]$} & {$[0.494,0.812]$} & {$[0.227,0.563]$} \\
C4 & {$[0.699,1.116]$} & {$[1.267,2.024]$} & {$[0.366,0.536]$} & {$[1.000,1.000]$} & {$[0.259,0.364]$} & {$[0.023,0.113]$} \\
C5 & {$[1.149,1.712]$} & {$[1.888,2.781]$} & {$[1.231,2.024]$} & {$[2.748,3.866]$} & {$[1.000,1.000]$} & {$[0.498,1.000]$} \\
\hline
\end{tabular}

proposed to decrease these effects while obtaining the weight scores and the decision matrix.

Then, after obtaining the weight scores and the decision matrix, grey MOORA method is applied to evaluate the public transport service quality. With grey MOORA application, the results will be obtained as ranges, which are grey numbers. This will also enable us to understand and read the ambiguities in the results.

This section is divided into two parts, which are obtaining the weight scores and the evaluation. The applications are done to evaluate public transport service quality and select suitable alternative for developing the public bus transport system in Budapest, Hungary. The pairwise comparisons are done by 10 experts from the faculty of transportation engineering, who are working on transport service quality. All application steps of the public transport service quality by using the proposed approach is given in detail in the following sub-sections. During the evaluation process, the experts took all bus lines in the network of Budapest in consideration.

The Municipality of Budapest runs the buses through The Budapest Transport Privately Held Corporation (BKV). In the last 10 years, citizens of Budapest have experienced an increase in public bus transport use, combined with a significant amount of investments by central government. The average age of the vehicles decreased slightly from 13.65 years to 13.57 years, in case of buses due to the purchases and new vehicles were purchased in 2017. Simultaneously with the renewal of the bus fleet, as a side effect, the number of buses equipped with airconditioning devices increases from 735 to 793 , the ratio from $73.6 \%$ to $79.5 \%$.

The framework of the proposed grey AHP-MOORA method used in this study is introduced step by step below.

\subsection{Obtaining the weight scores of the evaluation criteria and creating the decision matrix}

The first part of obtaining the weight scores and creating the decision matrix is defining the problem and constructing the hierarchical structure. First node of the hierarchical structure is the aim, which is the service quality. Then, the first branches are the main criteria. In this problem, we have five main criteria; approachability (C1), directness (C2), reliability (C3), time availability (C4) and speed (C5). The second branches, which are the branches of the first branches, are the sub-criteria. The last hierarchy is the alternatives; provide new buses, provide new routes and change stop locations. Provide new buses means to enhance citizens' accessibility which provide more frequent and consistent service, provide new routes similarly means providing new routes to reduce the number of transfer during travel, and change the stop location means changing the stop location to a more suitable location, so make it more approachable. The constructed hierarchical structure of the public bus transport system service quality applied in this study is shown in the Fig. 2.

Then, the next step is pairwise comparisons for each nodes of the hierarchical structure, combining them and obtaining the weights by using the calculation procedures given in the section 3.1 for the grey AHP. The combined pairwise comparison matrix for the main criteria is given in the following Table 3 . All of the pairwise comparisons done by the experts are combined by using the Eq. (4). After combining the pairwise comparisons of the experts, Table 3 is normalized by using the Eqs. (5)-(7) in Step 4 of the grey AHP. Then, final priority weights are obtained by calculating the average of the rows of Table 3 . The grey weights of the main criteria are given in the last column of the Table 3 .

While obtaining the priority weights and creating the decision matrix, Step 7 and Step 8 of the grey AHP is not applied. These steps are to evaluate the alternatives and for the decision. In this study, an integrated grey AHP-MOORA model will be applied to evaluate the public transport service quality in the section 4.2. Only main criteria weights given in Table 3 are whitened to weight the decision matrix in section 4.2.

Table 4 Whitened grey weights of the main criteria

\begin{tabular}{llll}
\hline & Grey Weights & $\begin{array}{l}\text { Whitened } \\
\text { Results }\end{array}$ & $\begin{array}{l}\text { Normalized } \\
\text { Whitened Results }\end{array}$ \\
\hline C1 & {$[0.092,0.267]$} & 0.159 & 0.1172 \\
C2 & {$[0.000,0.076]$} & 0.059 & 0.0437 \\
C3 & {$[0.227,0.563]$} & 0.346 & 0.2550 \\
C4 & {$[0.023,0.113]$} & 0.080 & 0.0593 \\
C5 & {$[0.498,1.000]$} & 0.712 & 0.5248 \\
\hline
\end{tabular}


Table 5 Calculating the final priority weights of the first criterion

\begin{tabular}{lllll}
\hline Weights & $\mathbf{0 . 6 6 6 0}$ & $\mathbf{0 . 3 0 6 6}$ & $\mathbf{0 . 0 2 7 4}$ & $\begin{array}{l}\text { Final Results } \\
\text { of C1 }\end{array}$ \\
Alternatives & $\mathbf{C 1 . 1}$ & $\mathbf{C 1 . 2}$ & $\mathbf{C 1 . 3}$ & \\
\hline A1 & {$[0.000,0.057]$} & {$[0.357,0.778]$} & {$[0.000,0.082]$} & {$[0.109,0.278]$} \\
A2 & {$[0.563,1.000]$} & {$[0.000,0.111]$} & {$[0.035,0.144]$} & {$[0.375,0.704]$} \\
A3 & {$[0.376,0.635]$} & {$[0.570,1.000]$} & {$[0.579,1.000]$} & {$[0.441,0.756]$} \\
\hline
\end{tabular}

Whitened results of the main criteria are given in the Table 4.

Such as the other MCDM methods, whitened results are normalized before using for the weight of the decision matrix.

Similar to the main node, criteria nodes are also calculated for the weights of the sub-criteria branches. In this step, each criteria node is like a small MCDM problem. The main criterion is like the aim of the problem and sub-criteria are like the criteria. The results of each five main criteria are given in the following tables respectively (Tables 5 and 6).

Criteria 3 (reliability) does not have any sub-criteria. Therefore, it is directly connected to the alternatives. The grey weights of the alternatives for criteria 3 is $[0.620,1.000],[0.031,0.082]$ and $[0.000,0.021]$ respectively (Tables 7 and 8).

The obtained grey weights of five main criteria is combined in the next step to construct the decision matrix and evaluate the public transport service quality. All of the weights and their rankings are combined and listed in the following Table 9.

4.2 The evaluation of the public transport service quality In this section, evaluation of the public transport service quality will be done by using the results obtained in the section 4.1. The grey weight results or grey final priority vectors are merged and the grey decision matrix shown in Table 10 is obtained. The main criteria weights are shown in the first line of the table. The priority vectors of the alternatives for each criterion are also shown in the related column of the criteria.

All of the applications using this table is done according to the calculation procedures given in the section 3.2. The obtained results of the grey MOORA are given in the

Table 6 Calculating the final priority weights of the second criterion

\begin{tabular}{llll}
\hline $\begin{array}{l}\text { Weights } \\
\text { Alternatives }\end{array}$ & $\mathbf{0 . 5 4 9 7}$ & $\mathbf{0 . 4 5 0 3}$ & $\begin{array}{l}\text { Final } \\
\text { Results } \\
\text { of C2 }\end{array}$ \\
\hline A1 & {$[0.000,0.197]$} & {$[0.405,0.942]$} & {$[0.182,0.532]$} \\
A2 & {$[0.502,1.000]$} & {$[0.397,1.000]$} & {$[0.454,1.000]$} \\
A3 & {$[0.026,0.276]$} & {$[0.000,0.331]$} & {$[0.014,0.300]$} \\
\hline
\end{tabular}

Table 7 Calculating the final priority weights of the fourth criterion

\begin{tabular}{llll}
\hline Weights & $\mathbf{0 . 8 8 9 0}$ & $\mathbf{0 . 1 1 0 9}$ & $\begin{array}{l}\text { Final } \\
\text { Results } \\
\text { of C4 }\end{array}$ \\
\hline Alternatives & $\mathbf{C 4 . 1}$ & $\mathbf{C 4 . 2}$ & {$[0.557,1.000]$} \\
A1 & {$[0.576,1.000]$} & {$[0.405,1.000]$} & {$[0.030,0.111]$} \\
A2 & {$[0.034,0.096]$} & {$[0.000,0.239]$} & {$[0.001,0.065]$} \\
A3 & {$[0.000,0.042]$} & {$[0.012,0.254]$} & \\
\hline
\end{tabular}

following table with their rankings. Also, the decision matrix of the public transport service quality is applied to grey AHP and classic MOORA [7] methods for the comparison and validation of the results. All of the obtained results of the three method is given in detail in the following table with their rankings. All of the he grey results are also normalized to make the comparison easier.

The obtained results show that the best alternative to ameliorate public transport service quality is providing new busses (A1) with 0.708 . The second alternative is providing new routes (A2) with 0.074 and the least preferable alternative is changing stop locations (A3) with 0.045 . When the results are observed in detail, we can say that providing new busses is by far the most important choice to ameliorate the service quality. The last two alternatives are not preferred options mostly by people. Therefore, there is much difference between the result of the first alternative and the other alternatives. Besides, all the results obtained by the proposed integrated grey AHP-MOORA method and the other methods are parallel to each other. Since there is no significant difference between the results of the methods, it can be said that the proposed grey AHP-MOORA method is useful, acceptable and applicable for the evaluation of the public transport service quality and also other MCDM problems (Fig. 3).

\section{Discussion}

It is becoming a difficult challenge for the governments as well as for the operators to find the most efficient solution to improve the service quality of public transportation. Particularly in Budapest, where hence, the final ranking of the alternatives will change.

The experts in the related field have evaluated each criteria and assigned their weigh scores in terms of

Table 8 Calculating the final priority weights of the fifth criterion

\begin{tabular}{|c|c|c|c|c|}
\hline Weights & 0.6131 & 0.1663 & 0.2206 & \\
\hline Alternatives & C5.1 & C5.2 & C5.3 & $\begin{array}{l}\text { Results } \\
\text { of C5 }\end{array}$ \\
\hline$\overline{\mathrm{A} 1}$ & {$[0.278,0.760]$} & {$[0.000,0.178]$} & {$[0.000,0.120]$} & {$[0.170,0.522]$} \\
\hline $\mathrm{A} 2$ & {$[0.433,1.000]$} & {$[0.448,1.000]$} & {$[0.120,0.351]$} & {$[0.366,0.856]$} \\
\hline $\mathrm{A} 3$ & {$[0.000,0.385]$} & {$[0.313,0.801]$} & {$[0.541,1.000]$} & {$[0.171,0.589]$} \\
\hline
\end{tabular}


Table 9 Weight scores and ranking of main criteria and sub-criteria

\begin{tabular}{|c|c|c|c|c|c|c|}
\hline Main Criteria & $\begin{array}{l}\text { Weights of the } \\
\text { Main Criteria }\end{array}$ & Rank & Sub-criteria & $\begin{array}{l}\text { Weights of the } \\
\text { Sub-criteria }\end{array}$ & Final Weights & Rank \\
\hline \multirow[t]{3}{*}{ C1: Approachability } & 0.1172 & 3 & C1.1 & 0.6660 & 0.0781 & 5 \\
\hline & & & $\mathrm{C} 1.2$ & 0.3066 & 0.0359 & 7 \\
\hline & & & $\mathrm{C} 1.3$ & 0.0274 & 0.0032 & 11 \\
\hline \multirow[t]{2}{*}{ C2: Directness } & 0.0437 & 5 & C2.1 & 0.5497 & 0.0240 & 8 \\
\hline & & & $\mathrm{C} 2.2$ & 0.4503 & 0.0197 & 9 \\
\hline C3: Reliability & 0.2550 & 2 & & & 0.2550 & 2 \\
\hline \multirow[t]{2}{*}{ C4: Time availability } & 0.0593 & 4 & C4.1 & 0.8890 & 0.0527 & 6 \\
\hline & & & $C 4.2$ & 0.1109 & 0.0066 & 10 \\
\hline \multirow[t]{3}{*}{ C5: Speed } & 0.5248 & 1 & C5.1 & 0.6131 & 0.3218 & 1 \\
\hline & & & C5.2 & 0.1663 & 0.0873 & 4 \\
\hline & & & C5.3 & 0.2206 & 0.1158 & 3 \\
\hline
\end{tabular}

linguistic variables, and the linguistic variables converted to grey values for completing computation process.

The weight scores and rankings of criteria of public transport service quality are depicted in Tables 9 and 11 . The main criteria and sub- criteria weight scores obtained by using AHP and the final weight scores and rank of sub- criteria are computed through multiplying the main criteria weight score with sub- criteria weight score. Among the 5 main criteria, Speed (0.5248) was the most significant issue and it took first rank. Speed criteria is represented in the second level by 3 subcriteria (Travel time, awaiting time and time to reach stops). The final weight score of Travel time (0.3218) make in the most important sub-criteria in sub-criteria level, followed by Time to reach stops $(0.1158)$ Awaiting time (0.0873). The demand of decreasing the journey's duration of time is not only important from experts perspective, but also, it is important for users as well [37]. Moreover, the spent time to arrive the bus stops is a significant issue for developing the service quality [34]. It is much more than important to satisfy users' needs, because, we do not want them to shift to other type of public transport or it can make them shift to their private cars. On the other hand, achieving users' expectations will attract non-users to start using public bus transport system. The second most significant main criteria were Reliability $(0.255)$. In general, the passengers want to get a reliable service [20,53]. In Budapest, using public bus system is a part the passengers' daily life to reach their destination.

Duleba and Moslem [24] conducted the conventional AHP to evaluate the supply quality of public transportation neglecting human vagueness, also they did not proposed any alternatives for improving the system. In our study, we spotted the light on improving public transport service quality by taking the experts perspectives, however, involving the citizens in the decision process would highlight their demand toward ameliorating the system.

The conducted findings in this study cannot be generalized for the all public bus transport systems in other cities in the world, hence, the rating of the criteria and alternatives will be different. On the other hand, the proposed model can be applied to evaluate the quality of public transport after modifying the hierarchical structure of the public transport service quality based on the existed system in the target city, then performing the proposed model.

\section{Conclusion and future research}

Grey AHP and Grey MOORA are not adopted together in a study based on the literature, particularly in solving public transportation problems. In our study, we present a first initiative to convey the Grey AHP-MOORA model for solving a real-world problem in transport sector. Moreover,

Table 10 Decision matrix of the public transport service quality

\begin{tabular}{llllll}
\hline Weights & $\mathbf{0 . 1 1 7 2}$ & $\mathbf{0 . 0 4 3 7}$ & $\mathbf{0 . 2 5 5 0}$ & $\mathbf{0 . 0 5 9 3}$ & $\mathbf{0 . 5 2 4 8}$ \\
Alternatives & C1 & C2 & C3 & C4 & C5 \\
\hline A1 & {$[0.109,0.278]$} & {$[0.182,0.532]$} & {$[0.620,1.000]$} & {$[0.557,1.000]$} & {$[0.170,0.522]$} \\
A2 & {$[0.375,0.704]$} & {$[0.454,1.000]$} & {$[0.031,0.082]$} & {$[0.030,0.111]$} & {$[0.366,0.856]$} \\
A3 & {$[0.441,0.756]$} & {$[0.014,0.300]$} & {$[0.000,0.021]$} & {$[0.001,0.065]$} & {$[0.171,0.589]$} \\
\hline
\end{tabular}




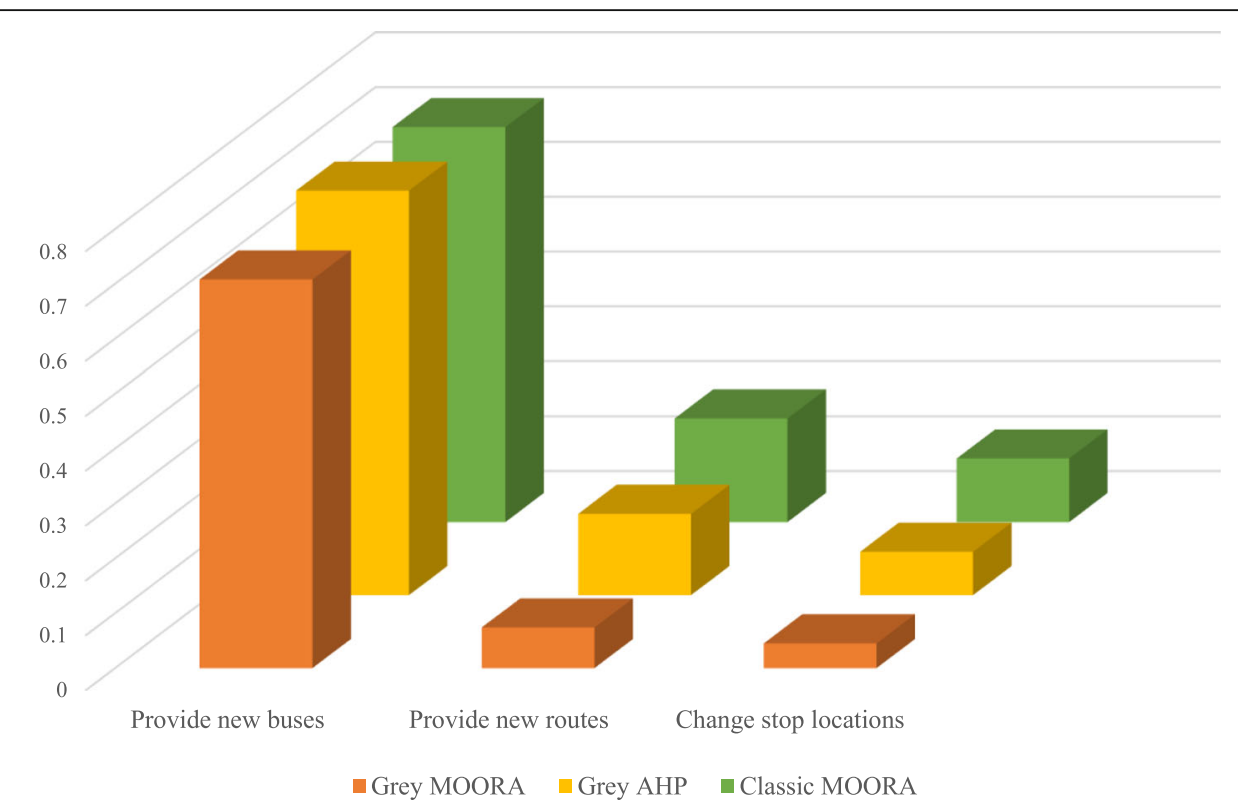

Fig. 3 The final scores of public bus transport service quality developing alternatives

MOORA has been enunciated as a best MCDM approach based on the numerical experiments, along with esteem to computational time and problem set up time.

This paper investigates the best alternative to develop the service quality of public transportation. The main criteria, sub-criteria and the alternatives utilized in this study have been determined by experts in the related field and based on the literature. The Grey AHP approach has been adopted to evaluate the importance of the main criteria and sub-criteria. The conducted results illustrated the speed as the most significant main criteria for improving the service quality of the system, which is impact efficiently the system quality. Furthermore, The Grey MOORA approach has been implemented to public transport service alternatives. The results and the applications show the effectiveness and the applicability of the approach. The presented methodology can not be only used for public transport service quality but also can be used for other branches of it.

Finally, the findings demonstrate that the most suitable alternative for improving the quality from the experts' perspective is providing new buses, followed by providing new routes and changing bus stop locations. The outcomes also show the importance of waiting time; it is important for all public transport users. However, providing new routes and changing bus stop locations will not be efficient to improve the quality of this issue as supplying new buses.

The adopted model in this study is essentially suitable for supporting strategic decision plans of the urban transportation system amelioration with respect to sustainability issues. Consequently, the obtained overall weights of criteria could be used for estimating and ranking projects aiming to improve the public bus transport system.

Our research can have a large scope of evaluators through sharing the users and non-users in the decision process, on the other hand, involving the local government representatives and comparing their perspectives with citizens' point of view can efficiently improve the future strategic improvement plan. The difference in preferences between the local government representatives and citizens can be detected by using Kendell agreement approach. The application can also be generalized for other countries and cities to improve the public transport systems. At the same time, through the

Table 11 Final results of the evaluation of the public transport service quality

\begin{tabular}{lllllllrr}
\hline Alt. & Grey AHP-MOORA Results & $\begin{array}{l}\text { Whitened } \\
\text { G-MOORA Results }\end{array}$ & R. & Grey AHP Results & $\begin{array}{l}\text { Whitened } \\
\text { G-AHP Results }\end{array}$ & R. & Classic MOORA & R. \\
\hline A1 & {$[0.566,1.000]$} & 0.708 & 1 & {$[0.516,1.000]$} & 0.737 & 1 & 0.720 & 1 \\
A2 & {$[0.030,0.121]$} & 2 & {$[0.060,0.276]$} & 0.148 & 2 & 0.189 \\
A3 & {$[0.000,0.055]$} & 0.074 & 3 & {$[0.000,0.166]$} & 0.079 & 3 & 0.116 & 2 \\
\hline
\end{tabular}

Alt Alternative, $R$ Ranking 
two-parts formation of the approach, it can be easily combined and improved with other MCDM and quantitative techniques according to the requirements of the applications. Furthermore, the presented grey MOORA methodology and the its application to the public transport service quality make a new and important contribution to both MCDM literature and public transport service quality literature.

In future researches, evaluating less number of pairwise comparisons in the survey save the effort and the time, a different MCDM approach or MCDM extensions can be adopted to minimize the pairwise comparisons number for computing criteria weight scores.

\section{Authors' contributions}

Sarbast Moslem and Yakup Çelikbilek conceptualized the research and created the suitable methodology. Sarbast Moslem conducted the survey and was responsible for the graphical representation of the results. Yakup Celikbilek was responsible for numerical analysis and computing the results. In paper writing both authors participated. The author(s) read and approved the final manuscript.

\section{Funding}

This research received no external funding.

\section{Availability of data and materials}

The datasets used and/or analyzed during the current study are available from the corresponding author on reasonable request.

\section{Competing interests}

The authors declare that they have no competing interests.

\section{Author details}

'Budapest University of Technology and Economics, Department of Transport Technology and Economics, Múegyetem rkp 3, Budapest 1111, Hungary. ${ }^{2}$ Department of Management Information Systems, Istanbul Gelisim University, 34310, Avcllar, Istanbul, Turkey.

Received: 24 April 2020 Accepted: 4 November 2020

Published online: 28 December 2020

\section{References}

1. Agrawal, R. (2008). Public transportation and customer satisfaction. Global Business Review, 9(2), 257-272.

2. Allen, J., Eboli, L., Forciniti, C., Mazzulla, G., \& de Dios Ortúzar, J. (2019). The role of critical incidents and involvement in transit satisfaction and loyalty. Transport Policy, 75, 57-69.

3. Allen, J., Eboli, L., Mazzulla, G., \& de Dios Ortúzar, J. (2020). Effect of critical incidents on public transport satisfaction and loyalty: An ordinal probit SEMMIMIC approach. Transportation, 47(2), 827-863.

4. Baradaran, V. (2017). Assessment and prioritizing the risks of urban rail transportation by using Grey analytical hierarchy process (GAHP). International Journal of Transportation Engineering, 4(4), 255-273.

5. Barzilai, J. (1997). Deriving weights from pairwise comparison matrices. Journal of the Operational Research Society, 48(12), 1226-1232.

6. Belwal, R., \& Belwal, S. (2010). Public transportation services in Oman: A study of public perceptions. Journal of Public Transportation, 13(4), 1.

7. Brauers, W. K., \& Zavadskas, E. K. (2006). The MOORA method and its application to privatization in a transition economy. Control and Cybernetics, 35, 445-469.

8. Cafiso, S., Di Graziano, A., \& Pappalardo, G. (2013). Using the Delphi method to evaluate opinions of public transport managers on bus safety. Safety Science, 57, 254-263.

9. Çelebi, D., \& Imre, Ş. (2020). Measuring crowding-related comfort in public transport. Transportation Planning and Technology, 43(7), 735-750.

10. Chang, Y. H., Wey, W. M., \& Tseng, H. Y. (2009). Using ANP priorities with goal programming for revitalization strategies in historic transport: A case study of the Alishan Forest railway. Expert Systems with Applications, 36(4), 8682-8690.

11. Chang, Y. H., \& Yeh, C. H. (2002). A survey analysis of service quality for domestic airlines. European Journal of Operational Research, 139(1), 166-177.

12. Cheng, Y. H., \& Tseng, W. C. (2016). Exploring the effects of perceived values, free bus transfer, and penalties on intermodal metro-bus transfer users' intention. Transport Policy, 47, 127-138.

13. Cheranchery, M. F., Bhattacharyya, K., Salih, M., \& Maitra, B. (2019). A proactive approach to assess safety level of urban bus stops. International Journal of Injury Control and Safety Promotion, 26(3), 260-270.

14. Chowdhury, S., \& van Wee, B. (2020). Examining women's perception of safety during waiting times at public transport terminals. Transport Policy, 94, 102-108.

15. Coppola, P., \& Silvestri, F. (2020). Assessing travelers' safety and security perception in railway stations. Case Studies on Transport Policy. In press. https://doi.org/10.1016/j.cstp.2020.05.006.

16. Currie, G. (2010). Quantifying spatial gaps in public transport supply based on social needs. Journal of Transport Geography, 18, 31-41.

17. De Oña, J., De Oña, R., Eboli, L., \& Mazzulla, G. (2013). Perceived service quality in bus transit service: a structural equation approach. Transport Policy, 29, 219-226.

18. Dell'Olio, L., Ibeas, A., \& Cecin, P. (2011). The quality of service desired by public transport users. Transport Policy, 18(1), 217-227.

19. Deng, Y., \& Yan, Y. (2019). Evaluating Route and Frequency Design of Bus Lines Based on Data Envelopment Analysis with Network Epsilon-Based Measures. Journal of Advanced Transportation, 2019.

20. Diab, E. I., Badami, M. G., \& El-Geneidy, A. M. (2015). Bus transit service reliability and improvement strategies: Integrating the perspectives of passengers and transit agencies in North America. Transport Reviews, 35(3), 292-328.

21. Dimitrov, S., Ceder, A., Chowdhury, S., \& Monot, M. (2017). Modeling the interaction between buses, passengers and cars on a bus route using a multi-agent system. Transportation Planning and Technology, 40(5), 592-610.

22. Duleba, S., Mishina, T., \& Shimazaki, Y. (2012). A dynamic analysis on public bus transport's supply quality by using AHP. Transport, 27(3), 268-275.

23. Duleba, S., \& Moslem, S. (2018). Sustainable urban transport development with stakeholder participation, an AHP-Kendall model: A case study for Mersin. Sustainability, 10(10), 3647.

24. Duleba, S., \& Moslem, S. (2019). Examining Pareto optimality in analytic hierarchy process on real data: An application in public transport service development. Expert Systems with Applications, 116, 21-30.

25. Dwivedi, S., \& Verma, N. (2017). Sustainability measurement of System's organization under Grey-knowledge based Ewz model using Grey-Moora approach. Asian Journal of Applied Science and Technology (AJAST), 1(8), 3137.

26. Eboli, L., \& Mazzulla, G. (2014). Investigating the heterogeneity of bus users' preferences through discrete choice modelling. Transportation Planning and Technology, 37(8), 695-710.

27. El-Geneidy, A. M., Horning, J., \& Krizek, K. J. (2011). Analyzing transit service reliability using detailed data from automatic vehicular locator systems. Journal of Advanced Transportation, 45(1), 66-79.

28. Friman, M., Fujii, S., Ettema, D., Gärling, T., \& Olsson, L. E. (2013). Psychometric analysis of the satisfaction with travel scale. Transportation Research Part A: Policy and Practice, 48, 132-145.

29. Gercek, H., Karpak, B., \& Kilncaslan, T. (2004). A multiple criteria approach for the evaluation of the rail transit networks in Istanbul. Transportation, 31, 203-228.

30. Ghorbanzadeh, O., Moslem, S., Blaschke, T., \& Duleba, S. (2019). Sustainable urban transport planning considering different stakeholder groups by an interval-AHP decision support model. Sustainability, 11(1), 9.

31. Güner, S. (2018). Measuring the quality of public transportation systems and ranking the bus transit routes using multi-criteria decision making techniques. Case Studies on Transport Policy, 6(2), 214-224.

32. Hernandez, S., Monzon, A., \& de Oña, R. (2016). Urban transport interchanges: A methodology for evaluating perceived quality. Transportation Research Part A: Policy and Practice, 84, 31-43.

33. Hutchinson, T. P. (2009). The customer experience when using public transport: A review. Proceedings of the ICE-Municipal Engineer, 162(3), 149157.

34. Ingvardson, J. B., Nielsen, O. A., Raveau, S., \& Nielsen, B. F. (2018). Passenger arrival and waiting time distributions dependent on train service frequency 
and station characteristics: A smart card data analysis. Transportation Research Part C: Emerging Technologies, 90, 292-306.

35. Jharkharia, S., \& Shankar, R. (2007). Selection of logistics service provider: An analytic network process (ANP) approach. Omega, 35(3), 274-289.

36. Jin, Z., Schmöcker, J. D., \& Maadi, S. (2019). On the interaction between public transport demand, service quality and fare for social welfare optimisation. Research in Transportation Economics, 76, 100732.

37. Kujala, R., Weckström, C., Mladenović, M. N., \& Saramäki, J. (2018). Travel times and transfers in public transport: Comprehensive accessibility analysis based on Pareto-optimal journeys. Computers, Environment and Urban Systems, 67, 41-54

38. Kumar Sahu, A., Datta, S., \& Sankar Mahapatra, S. (2014). Supply chain performance benchmarking using grey-MOORA approach: An empirical research. Grey Systems: Theory and Application, 4(1), 24-55.

39. Lai, W.-T., \& Chen, C.-F. (2010). Behavioral intentions of public transit passengers - The roles of service quality, perceived value. satisfaction and involvement. Transport Policy, 18(2), 318-325.

40. Li, W., Yu, S., Pei, H., Zhao, C., \& Tian, B. (2017). A hybrid approach based on fuzzy AHP and 2-tuple fuzzy linguistic method for evaluation in-flight service quality. Journal of Air Transport Management, 60, 49-64.

41. Lupo, T. (2013). Handling stakeholder uncertain judgments in strategic transport service analyses. Transport Policy, 29, 54-63.

42. Miao, Q., Welch, E. W., \& Sriraj, P. S. (2019). Extreme weather, public transport ridership and moderating effect of bus stop shelters. Journal of Transport Geography, 74, 125-133.

43. Mokonyama, M., \& Venter, C. (2013). Incorporation of customer satisfaction in public transport contracts-a preliminary analysis. Research in Transportation Economics, 39(1), 58-66.

44. Moslem, S., Ghorbanzadeh, O., Blaschke, T., \& Duleba, S. (2019). Analysing stakeholder consensus for a sustainable transport development decision by the fuzzy AHP and interval AHP. Sustainability, 11(12), 3271.

45. Murray, A. T. (2003). A coverage model for improving public transit system accessibility and expanding access. Annals of Operations Research, 123(1-4), 143-156.

46. Nalmpantis, D., Roukouni, A., Genitsaris, E., Stamelou, A., \& Naniopoulos, A. (2019). Evaluation of innovative ideas for public transport proposed by citizens using multi-criteria decision analysis (MCDA). European Transport Research Review, 11(1), 22.

47. Nesheli, M. M., Ceder, A. A., \& Brissaud, R. (2017). Public transport servicequality elements based on real-time operational tactics. Transportation, 44(5), 957-975.

48. Porcu, F., Olivo, A., Maternini, G., \& Barabino, B. (2020). Evaluating bus accident risks in public transport. Transportation Research Procedia, 45, 443450.

49. Saaty, T. L. (1977). A scaling method for priorities in hierarchical structures. Journal of Mathematical Psychology, 15(3), 234-281.

50. Saif, M. A., Zefreh, M. M., \& Torok, A. (2019). Public transport accessibility: A literature review. Periodica Polytechnica Transportation Engineering, 47(1), 3643.

51. Saito, M. (1987). Application of the analytic hierarchy method to setting priorities on bridge replacement projects, transportation research record. Transportation Research Record, 1124, 26-35.

52. Scott, N., Hart, A., Wilson, J., Livingston, M., Moore, D., \& Dietze, P. (2016). The effects of extended public transport operating hours and venue lockout policies on drinking-related harms in Melbourne, Australia: Results from SimDrink, an agent-based simulation model. International Journal of Drug Policy, 32, 44-49.

53. Soza-Parra, J., Raveau, S., Muñoz, J. C., \& Cats, O. (2019). The underlying effect of public transport reliability on users' satisfaction. Transportation Research Part A: Policy and Practice, 126, 83-93.

54. Sun, S., Fang, D., \& Cao, J. (2020). Exploring the asymmetric influences of stop attributes on rider satisfaction with bus stops. Travel Behaviour and Society, 19, 162-169.

55. Tabucanon, M. T., \& Lee, H. (1995). Multiple criteria evaluation of transportation system improvement projects: The case of Korea. Journal of Advanced Transportation, 29(1), 127-134

56. Tétreault, P. R., \& El-Geneidy, A. M. (2010). Estimating bus run times for new limited-stop service using archived AVL and APC data. Transportation Research Part A: Policy and Practice, 44(6), 390-402.

57. Tracz, M., \& Wawrzynkiewicz, B. (1993). Knowledge acquisition from multiple experts: A case of transport planning in Poland (chapter 14). In J. R. Wright,
L. L. Wiggins, R. K. Jain, \& T. J. Kim (Eds.), Expert system in environmental planning, (pp. 261-274). Berlin Heidelberg: Springer-Verlag.

58. Tsaur, S. H., Chang, T. Y., \& Yen, C. H. (2002). The evaluation of airline service quality by fuzzy MCDM. Tourism Management, 23(2), 107-115.

59. Tsionas, M. G., Chen, Z., \& Wanke, P. (2017). A structural vector autoregressive model of technical efficiency and delays with an application to Chinese airlines. Transportation Research Part A: Policy and Practice, 101, $1-10$.

60. Van Lierop, D., Badami, M. G., \& El-Geneidy, A. M. (2018). What influences satisfaction and loyalty in public transport? A review of the literature. Transport Reviews, 38(1), 52-72.

61. Vos, M. C., \& van Hagen, M. (2019). Objective and subjective predictors of perceived cleanliness in train stations. Transportation Research Procedia, 42, 109-117.

62. Wang, W., \& Liu, P. (2007). The evaluation of urban public traffic line network based on the grey-AHP method. In International conference on transportation engineering 2007, (pp. 1991-1996).

63. Wu, W. W., \& Lee, Y. T. (2007). Developing global managers' competencies using the fuzzy DEMATEL method. Expert systems with applications, 32(2), 499-507.

64. Yaya, L. H. P., Fortià, M. F., Canals, C. S., \& Marimon, F. (2015). Service quality assessment of public transport and the implication role of demographic characteristics. Public Transport, 7(3), 409-428.

\section{Publisher's Note}

Springer Nature remains neutral with regard to jurisdictional claims in published maps and institutional affiliations.

\section{Submit your manuscript to a SpringerOpen ${ }^{\circ}$ journal and benefit from:}

- Convenient online submission

- Rigorous peer review

- Open access: articles freely available online

- High visibility within the field

- Retaining the copyright to your article

Submit your next manuscript at $\boldsymbol{\nabla}$ springeropen.com 